\title{
Supply Chain Risk Analysis With MAFMA Method Approach
}

\author{
Fatimah, Indah Asmara, Sri Mutia, M Sayuti \\ Department of Industrial Engineering, Universitas Malikussaleh, Aceh, Indonesia \\ *Corresponding author E-mail: fatimah@yahoo.com
}

\begin{abstract}
Manuscript received 15 August 2021; revised 1 Sept 2021; accepted 15 Sept 2021. Date of publication 4 Nov 2021

Palm oil mill is a palm oil and palm kernel processing industry which is a semi-finished product. The palm oil industry is currently growing rapidly in line with the demand for large quantities of CPO and Kernal and their derivatives. In its operation, it is always faced with various risks, from the field to the processing plant. These risks will cause losses to the factory, especially in the form of financial. From the results of field observations obtained 13 kinds of supply chain risks, namely damaged trucks, FFB not up to standard, damaged FFB, insufficient FFB, network error, FFB damaged in the sorting field, boiling problems, problematic polisyndrom, abnormal steem, abnormal processes. /stops, viber cyclone plugs and leaks pipe. Therefore, it is necessary to identify, measure and manage risks to reduce losses caused by supply chain risks. The method used in this study is the MAFMA (Multi Attribute Failure Mode Analysis) method. The MAFMA method is a development of the FMEA method. The results showed that the risk level value contained 4 critical risks on the part of the factory, namely FFB less with a risk level value of 0.096, FFB not according to standards with a risk level value of 0.085 , network error with a risk level value of 0.083 and the process running abnormally. /stop with a risk level of 0.073 . These 4 critical risks are the priority to be handled. The handling carried out is planning for the right FFB procurement, providing guidance on the harvesting process, stabilizing the network by providing copper rods and planning machine scheduling.
\end{abstract}

Keywords: Risk, Supply Chain, Multi Attribute Failure Mode Analysis, Failure Mode and Effect Analysis.

\section{Introduction}

Indonesia is a country that has abundant natural resources, one of which is oil palm. It is known that Indonesia is the largest producer of palm oil in the world, with a plantation area of 12.76 million hectares (BPS). The extent of oil palm plantations in Indonesia makes it easier for the management of palm oil mills to obtain the raw materials needed for the production process. PT. X is a palm oil mill located in Aceh Singkil, in the production process, this company uses raw materials from its own oil palm plantations and also from oil palm plantations owned by local communities. In its operation, factory management is always faced with various risks, ranging from risks in the field of financial form. From the results of field observations, it was found that 13 kinds of supply chain risks, namely damaged transport trucks, FFB not according to standards, damaged FFB, insufficient FFB, network error, damaged FFB in the sorting field, boiling problems, problematic polysyndrome, abnormal steem, the process is not running. normal/stopped, viber cyclone plug and leaking pipe. These risks occur on the part of the supplier and part of the factory.

Based on these problems, it is necessary to conduct an analysis to determine the causes of the emergence of risks and how to deal with these risks. The method used in handling this risk is by using the MAFMA method

\section{Literature Review}

\subsection{Risk Management}

Risk management is an effort made to identify, identify and analyze a risk that is likely to occur and the steps taken in handling the risk that occurs. Risk management can identify risks, assess risks and reduce the likelihood of risks occurring. Risk management has components that can distinguish it from other business management, namely the internal environment, target setting, event identification, risk assessment, risk response, control activities, information and communication and monitoring. This instrument must be in the new management, the implementation process can be carried out optimally [1] [2] [3]. 


\subsection{Risk and Uncertainty}

The term risk is often equated with the term uncertainty even though the two clearly have differences, namely risk has a greater chance of happening than uncertainty. Meanwhile, according to Vaughan (1997), uncertainty is caused by a lack of information about what will happen or not in the future. Meanwhile, risk is future damage that can arise from some activities carried out at this time [4]. Adverse events that occur in the future cannot be $100 \%$ certain, but these risks have a probability of occurrence. This is what makes the distinction clear that risk and uncertainty are not the same.

\subsection{Supply Chain Management}

Many theories put forward by experts about what is supply chain management (supply chain management), one of which is the theory of Ballou. Supply chain management (Supply Chain Management) is the integration of activities through improving supply chain relationships to achieve a sustainable competitive advantage, supply chain management emphasizes the interactions that occur between marketing, logistics, and production functions within a company and the interactions that occur between companies. legally separated company in product flow [5][6][7]. Supply chain management emphasizes the interaction between marketing and production functions in a company [1][8][9]. Supply chain management prioritizes the flow of goods between companies, from the beginning of the activity to the final product [10][7]. While the goal is based on cooperation and seeking relationships and coordination between processes from partner companies to support process activities to consumers Ballou [5].

\subsection{Failure Mode and Effect Analysis (FMEA) Method}

FMEA is a method of evaluating the possibility of a failure of a system, design, process or service to be handled [11]. Failure mode and effect analysis is a method that is often used to identify components that cause risk and then prevent problems that occur [12] [13][14].

\subsection{Analytical Hierarchy Process (AHP)}

In the manufacturing or service industries, decision making will be a complex problem [15][16]. The analytical hierarchy process is often used to solve multi-criteria decision making (MCDM) problems. This method was created by Saaty at the University of Pittsburgh. AHP itself offers a method that is very relatively easy to do and able to evaluate existing alternatives [17]. AHP allows for decision making to use simple hierarchical forms for solving quite complex problems and evaluating qualitative and quantitative data in a systematic methodology with attention to multiple criteria. [18] [11] [19].

\subsection{Multi Attribute Failure Mode Analysis (MAFMA) Method}

MAFMA is a method developed by Marcello Braglia that combines AHP and FMEA. The AHP merger aims to overcome the weaknesses of the FMEA method. In FMEA only consider three criteria, namely severity, occurrence and detectability. However, there is one factor that is no less important than the three criteria to be included, namely economic considerations. This lack of consideration of the economic aspect is the weakness of FMEA itself [20] [21][15].

\section{Methods}

There are several steps of the MAFMA method developed by Braglia (Braglia, 2000). In this study used to analyze the supply chain, namely:

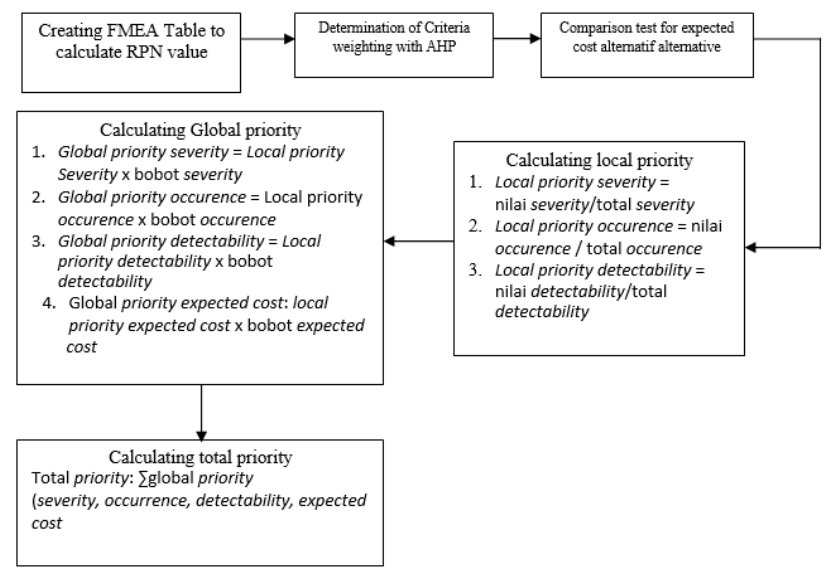

Fig 1. Troubleshooting steps with MAFMA

\section{Results and Discussion}

The risk data obtained after identification by means of free interviews with related parties are as follows:

1. Risk on the part of the supplier

a. TBS is not up to standard

b. FFB broken

c. The haul truck broke down on the way

2. Risk on the part of the factory

a. shortage of FFB raw materials from plantations

b. network error

c. FFB damaged in the sorting field 
d. TBS is not up to standard

e. problem boiling

f. polishing drum

g. steam is not normal

$\mathrm{h}$. the process is running abnormally/stopped

i. viber cycle plug

j. pipe leak

\subsection{FMEA Calculation}

After setting the ranking for each criterion of Severity, Occurrence and Detectebility, the value of RPN (Risk Priority Number) can then be calculated by multiplying $\mathrm{S} \times \mathrm{O}$ x D. The results of the multiplication of RPN for the supply chain of palm oil for the supplier part and the mill part are obtained from the FMEA Table.

Table 1. Total Multiplication Results of RPN

\begin{tabular}{ll}
\hline Rantai Pasok & Total RPN \\
\hline Pemasok & 120 \\
\hline Pabrik & 1261 \\
\hline
\end{tabular}

\subsection{AHP Calculation}

a. Priority Determination

1. Questionnaire processing I paired comparison test between criteria.

For processing the questionnaire I used an expert choice application by taking four criteria, namely severity, occurrence, detectability and expected cost. Weight of criteria according to respondent I

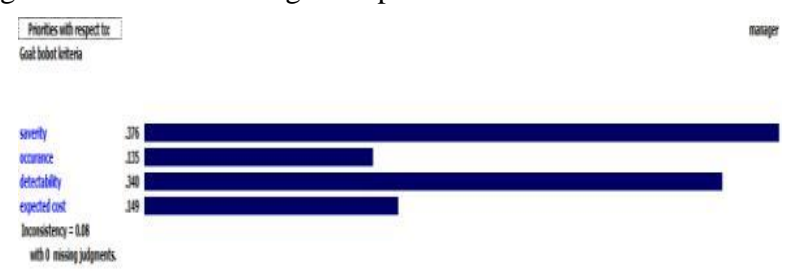

Fig1. Weight of response criteria I

From the graph above, it can be explained that the severity criteria are higher or more important than the three existing criteria. Weight of criteria according to respondent II

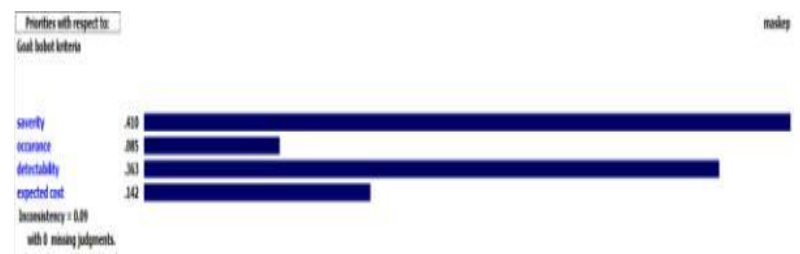

Fig 2. Weight of respondent criteria II

From the graph above, it can be explained that the severity criteria are higher or more important than the three existing criteria.

b. Questionnaire II Paired Comparison Test Cost Criteria

Estimated costs in the supply chain

In the processing of the second questionnaire, it is processed in an expert choice application with the criteria taken are the causes of risk in the supply chain. In the supplier section, three criteria are used, while in the factory section, ten criteria are used.

Table 2. Priority of cost estimates for risk

\begin{tabular}{|c|c|c|}
\hline Priority & Risk & $\begin{array}{c}\text { Local } \\
\text { Priority } \\
\end{array}$ \\
\hline \multicolumn{3}{|l|}{ Supplier } \\
\hline \multirow[t]{2}{*}{0.258} & There are pests and weeds & 0.038 \\
\hline & on oil palm & \\
\hline 0.058 & Workers not according to SOP & 0.003 \\
\hline \multirow[t]{2}{*}{0.663} & Less engine maintenance & 0.033 \\
\hline & Inconsistency $=0.05$ & \\
\hline \multicolumn{3}{|l|}{ Factory } \\
\hline 0.287 & Fruit ripeness varies & 0.026 \\
\hline 0.100 & Weather/Lightning & 0.009 \\
\hline 0.019 & Not using the FIFO system & 0.002 \\
\hline 0.185 & Abnormal FFB/raw FFB & 0.017 \\
\hline 0.050 & FFB is less stable when & \\
\hline
\end{tabular}




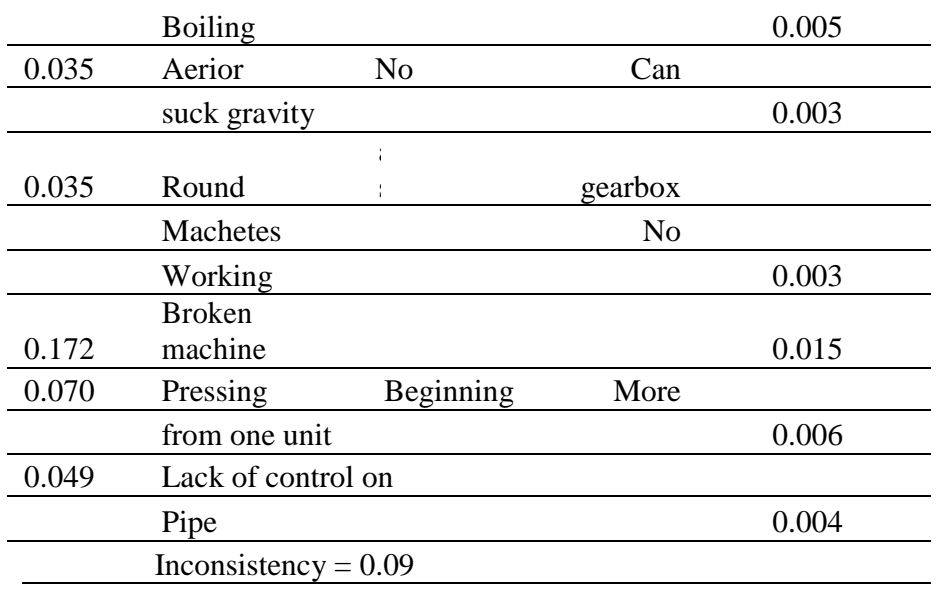

\subsection{MAFMA Calculation}

MAFMA calculation starts from looking for local priority (severity, occurrence and detectability) to the level of risk.

Table 3. Risk levels for supply chain risk causes

\begin{tabular}{|c|c|c|c|c|c|c|c|c|c|}
\hline \multirow[b]{3}{*}{ Causes of Risk } & \multicolumn{4}{|c|}{ Local priority } & \multicolumn{4}{|c|}{ Global priority } & \multirow[b]{3}{*}{$\begin{array}{l}\text { Risk } \\
\text { Level }\end{array}$} \\
\hline & \multirow{2}{*}{$\begin{array}{l}\mathrm{S}=89 \\
\mathrm{~S}\end{array}$} & \multirow{2}{*}{$\begin{array}{l}\mathrm{S}=78 \\
\mathrm{O}\end{array}$} & \multirow{2}{*}{$\begin{array}{l}\mathrm{S}=34 \\
\mathrm{D}\end{array}$} & \multirow[b]{2}{*}{$\mathrm{C}$} & \multirow{2}{*}{$\begin{array}{l}0.376 \\
S\end{array}$} & \multirow{2}{*}{$\begin{array}{l}0.065 \\
\mathrm{O}\end{array}$} & \multirow{2}{*}{$\begin{array}{l}0.423 \\
\mathrm{D}\end{array}$} & \multirow{2}{*}{$\begin{array}{l}0.135 \\
\mathrm{C}\end{array}$} & \\
\hline & & & & & & & & & \\
\hline \multicolumn{10}{|l|}{ Supplier Part } \\
\hline $\begin{array}{l}\text { There are pests and weeds } \\
\text { on oil palm plants }\end{array}$ & 0.079 & 0.077 & 0.029 & 0.038 & 0.030 & 0.005 & 0.012 & 0.005 & 0.055 \\
\hline $\begin{array}{l}\text { Workers not according to } \\
\text { SOP }\end{array}$ & 0.067 & 0.064 & 0.029 & 0.003 & 0.025 & 0.004 & 0.012 & 0 & 0.045 \\
\hline Less engine maintenance & 0.045 & 0.077 & 0.059 & 0.033 & 0.017 & 0.005 & 0.025 & 0.004 & 0.052 \\
\hline \multicolumn{10}{|l|}{ Factory Part } \\
\hline Fruit ripeness varies & 0.101 & 0.090 & 0.118 & 0.026 & 0.038 & 0.006 & 0.050 & 0.003 & 0.097 \\
\hline Weather/Lightning & 0.056 & 0.064 & 0.147 & 0.009 & 0.021 & 0.004 & 0.062 & 0.001 & 0.089 \\
\hline Do not use the FIFO system & 0.034 & 0.038 & 0.147 & 0.002 & 0.013 & 0.003 & 0.062 & 0.000 & 0.078 \\
\hline Abnormal FFB/raw FFB & 0.101 & 0.103 & 0.088 & 0.017 & 0.038 & 0.007 & 0.037 & 0.002 & 0.084 \\
\hline $\begin{array}{l}\text { FFB is less stable when boil- } \\
\text { ing }\end{array}$ & 0.079 & 0.064 & 0.088 & 0.005 & 0.030 & 0.004 & 0.037 & 0.001 & 0.072 \\
\hline Aerial can't suck gravity & 0.079 & 0.064 & 0.059 & 0.003 & 0.030 & 0.004 & 0.025 & 0.000 & 0.059 \\
\hline $\begin{array}{l}\text { The machete gearbox axle } \\
\text { doesn't work }\end{array}$ & 0.079 & 0.090 & 0.059 & 0.003 & 0.030 & 0.006 & 0.025 & 0.000 & 0.061 \\
\hline Broken machine & 0.101 & 0.090 & 0.059 & 0.015 & 0.038 & 0.006 & 0.025 & 0.002 & 0.071 \\
\hline $\begin{array}{l}\text { Pre-pressing more than one } \\
\text { unit }\end{array}$ & 0.090 & 0.090 & 0.059 & 0.006 & 0.034 & 0.006 & 0.025 & 0.001 & 0.065 \\
\hline Lack of control on the pipe & 0.090 & 0.090 & 0.059 & 0.004 & 0.034 & 0.006 & 0.025 & 0.001 & 0.065 \\
\hline
\end{tabular}

\subsection{Risk Handling and Control}

From the results of the MAFMA analysis, the risks that have the highest level of risk that require further control are:

a. Less FFB (factory part)

b. Network error

c. TBS is not up to standard

d. FFB damaged in the sorting field

In an effort to minimize the impact and the possibility of negative risks, there are several strategies that can be applied, namely avoidance, mitigation. Risk management strategies that can be provided include:

1. less TBS

a. Avoidance strategy Proper FFB procurement planning

b. Mitigation strategy

In this strategy, so that there is no shortage of FFB, it is necessary to ensure that FFB is on demand, then it is also necessary to pay attention to workers who harvest on plantations so that they do not harvest carelessly who do not pay attention to proper fruit maturity. Then you can also increase FFB receipts from third parties

2. FFB is not up to standard

a. Avoidance strategy Regular maintenance of oil palms

b. Mitigation strategy

To reduce the risk of abnormal FFB, it is necessary to pay attention to workers who carry out the process of harvesting fruit taken from their own plantations. Provide assistance to local oil palm farmers through technical assistance on harvesting methods so that they can harvest FFB properly and according to standards. 


\section{Network error}

For the network, this error is risky because the company does the weighing automatically, so when the weather is unstable the network must be turned off which has an impact on the weighing stop. What needs to be done is to keep the network stabilized so that it can still do the weighing. Also can be given a copper rod which is a tool for anti-lightning.

4. FFB damaged in the sorting field

a. Avoidance strategy Workers according to SOP

b. Mitigation strategy

Supervise workers, take FFB in accordance with the use of the FIFO system.

\section{Conclusion}

To find out the most impactful risks to be prioritized according to the weight of the criteria determined by the company's management. The criteria used are severity, occurrence, detectability and expected cost. And for the results of the pairwise comparison test of the four criteria, the value of each criterion weight is $37.6 \%$, the occurrence criterion is $6.5 \%$, the detectability criterion is $42.3 \%$ and the expected cost criterion is $13.5 \%$. Based on the weight of the criteria obtained, in the factory section the highest risk level value is less than 0.097 FFB, the network error risk level is 0.089 , FFB is not in accordance with the standard risk level of 0.084 and the last FFB is damaged in the sorting field with a risk level value of 0.078 . for the supplier, the highest risk level value is found in pests and weeds in oil palm plantations of 0.055 and less machine maintenance with a risk level value of 0.052 . The parts that have the highest level of risk indicate that these parts need handling and control.

\section{References}

[1] O. Lavastre, A. Gunasekaran, and A. Spalanzani, "Supply chain risk management in French companies," Decis. Support Syst., vol. 52, no. 4, pp. 828-838, Mar. 2012, doi: 10.1016/j.dss.2011.11.017.

[2] D. G. Hoffman, Managing Operational Risk: 20 Firmwide Best Practice Strategies. Wiley, 2002.

[3] Y. K. Tse, M. Zhang, K. H. Tan, K. Pawar, and K. Fernandes, "Managing quality risk in supply chain to drive firm's performance: The roles of control mechanisms," J. Bus. Res., vol. 97, pp. 291-303, Apr. 2019, doi: 10.1016/j.jbusres.2018.01.029.

[4] J. . Vaughan, Risk Management. New Jersey: John Wiley\&Sons, Inc., 1997.

[5] A. I. Pettersson and A. Segerstedt, "Measuring supply chain cost," Int. J. Prod. Econ., vol. 143, no. 2, pp. 357-363, Jun. 2013, doi: 10.1016/j.ijpe.2012.03.012.

[6] D. M. Lambert and M. C. Cooper, "Issues in Supply Chain Management," Ind. Mark. Manag., vol. 29, no. 1, pp. 65-83, Jan. 2000, doi: 10.1016/S0019-8501(99)00113-3.

[7] S. Samad et al., "Green Supply Chain Management practices and impact on firm performance: The moderating effect of collaborative capability,” Technol. Soc., vol. 67, p. 101766, Nov. 2021, doi: 10.1016/j.techsoc.2021.101766.

[8] G. Li, H. Fan, P. K. C. Lee, and T. C. E. Cheng, "Joint supply chain risk management: An agency and collaboration perspective," Int. J. Prod. Econ., vol. 164, pp. 83-94, Jun. 2015, doi: 10.1016/j.ijpe.2015.02.021.

[9] M. Munir, M. S. S. Jajja, K. A. Chatha, and S. Farooq, "Supply chain risk management and operational performance: The enabling role of supply chain integration," Int. J. Prod. Econ., vol. 227, p. 107667, Sep. 2020, doi: 10.1016/j.ijpe.2020.107667.

[10] J. Hong, Y. Zhang, and M. Ding, "Sustainable supply chain management practices, supply chain dynamic capabilities, and enterprise performance," J. Clean. Prod., vol. 172, pp. 3508-3519, Jan. 2018, doi: 10.1016/j.jclepro.2017.06.093.

[11] R. K. Aslani, H. R. Feili, and H. Javanshir, "A hybrid of fuzzy FMEA-AHP to determine factors affecting alternator failure causes," Manag. Sci. Lett., vol. 4, no. 9, pp. 1981-1984, 2014.

[12] G. Cassanelli, G. Mura, F. Fantini, M. Vanzi, and B. Plano, "Failure Analysis-assisted FMEA," Microelectron. Reliab., vol. 46, no. 9-11, pp. 1795-1799, Sep. 2006, doi: 10.1016/j.microrel.2006.07.072.

[13] N. Xiao, H.-Z. Huang, Y. Li, L. He, and T. Jin, "Multiple failure modes analysis and weighted risk priority number evaluation in FMEA," Eng. Fail. Anal., vol. 18, no. 4, pp. 1162-1170, Jun. 2011, doi: 10.1016/j.engfailanal.2011.02.004.

[14] A. Hassan, M. R. A. Purnomo, and A. R. Anugerah, "Fuzzy-analytical-hierarchy process in failure mode and effect analysis (FMEA) to identify process failure in the warehouse of a cement industry," J. Eng. Des. Technol., vol. 18, no. 2, pp. 378-388, Sep. 2019, doi: 10.1108/JEDT-05-2019-0131.

[15] K.-S. Chin, Y.-M. Wang, G. Ka Kwai Poon, and J.-B. Yang, "Failure mode and effects analysis using a group-based evidential reasoning approach," Comput. Oper. Res., vol. 36, no. 6, pp. 1768-1779, Jun. 2009, doi: 10.1016/j.cor.2008.05.002.

[16] R. Fattahi and M. Khalilzadeh, "Risk evaluation using a novel hybrid method based on FMEA, extended MULTIMOORA, and AHP methods under fuzzy environment," Saf. Sci., vol. 102, pp. 290-300, Feb. 2018, doi: 10.1016/j.ssci.2017.10.018.

[17] O. Oktamianiza, D. Maisa Putra, Y. Yulia, A. Fahira, and A. Afridon, "Analysis of Differences in Tariff for Health Service Based on Sustability of Diagnosis on Admision and Summary Discharge Form with INA-CBGs Verification," Int. J. Eng. Sci. Inf. Technol., vol. 1, no. 3, 2021, doi: 10.52088/ijesty.v1i3.114.

[18] N. Khalil, S. N. Kamaruzzaman, and M. R. Baharum, "Ranking the indicators of building performance and the users' risk via Analytical Hierarchy Process (AHP): Case of Malaysia," Ecol. Indic., vol. 71, pp. 567-576, Dec. 2016, doi: 10.1016/j.ecolind.2016.07.032.

[19] H. Li, H. Díaz, and C. Guedes Soares, "A failure analysis of floating offshore wind turbines using AHP-FMEA methodology," Ocean Eng., vol. 234, p. 109261, Aug. 2021, doi: 10.1016/j.oceaneng.2021.109261.

[20] M. Braglia, "MAFMA: multi-attribute failure mode analysis," Int. J. Qual. Reliab. Manag., vol. 17, no. 9, pp. 1017-1033, Dec. 2000, doi: 10.1108/02656710010353885.

[21] K.-H. Chang, "Generalized multi-attribute failure mode analysis," Neurocomputing, vol. 175, pp. 90-100, Jan. 2016, doi: 10.1016/j.neucom.2015.10.039. 